\title{
Indian Academy of Pediatrics National Conference (CIAP-PEDICON), 5th February, 2021, Mumbai
}

\author{
Piyush Gupta \\ National President, Indian Academy of Pediatrics 2021 \\ president@iapindia.org
}

T

hink of where we were a hundred years ago. Just out of the throes of a pandemic that infected one third of the world's population. There were no antibiotics, no ventilators, no RNA vaccines, no RT-PCR, no genome sequencing; 500 million infected and a 50 million dead in 2 years [1]. Now think of where we are today a century later. In the middle of another pandemic; 2 million dead, 100 million infected. Yet, we are not as helpless as we used to be. Mankind has produced multiple working vaccines in record time. We have industrial output to match demand of facemasks and other personal protective equipment in hundreds of million. It's been difficult and trying time for society at large. However, thereis no doubt that this experience will leave us better prepared to fight the next battle. It will transform the challenges in front of and augment us as medical practitioners and custodians of the health and wellbeing of the next generation.

The pandemic taught us that it's imperative to recognize and acknowledge the problem before we can mobilize to tackle it. Until there was consensus on the unprecedented nature of Covid-19 and its imminent threat of turning into a full-blown pandemic, it was impossible to come to a global effort to contain and minimize it. Travel bans, mandatory masking, home isolation, quarantines etc were put in place only when the disease was already spreading, to be able to make a major difference.

COVID is here to stay and so are we; but as the time passes, we are gaining an edgeover the virus. Indian Academy of Pediatrics salutes those pediatricians who have laid down than lives fighting it or have struggled the illness with all their might to conquer the disease. Mission Co-Win Uday under the action plan of the Indian Academy of Pediatrics is a small tribute to all these warriors. Initiating with a training of trainers, the sensitization module for pediatricians covers various facets of coronavirus disease among pediatricians and children, COVID-19 vaccines, and its psychosocial impact. Mission Co-Win Uday symbolizes the rising of the pediatrician and is an effort to gear them for a win in this war. More than
100 trainers are being trained in this Pedicon to start a cascade of imparting knowledge and skills on COVIDrelated issues nationwide, in the coming year.

\section{PARENTS AND THE INDIAN ACADEMY OF PEDIATRICS}

So when we focus on the coming, evolved era of child healthcare, we must recognize that it's a landscape we are unfamiliar with, one with increasingly complex and interdependent challenges. We must be ready for a paradigm shift from being mere healers- to feelers, friends, philosophers and guides to children as well as their parents.

Unfortunately, there is a communication gap between the Indian Academy of Pediatrics (the custodian of child health) and the parents (actual caregivers to the children). To fill this gap, Indian Academy of Pediatrics has started constructing bridges to connect the Academy and the Parents. We have been working on a unique project for developing 101 Guidelines for parents for last 6 months. I am happy to announce that the first of these Guidelines was launched on 11 January 2021. As promised, we will be releasing at least one guideline every week throughout the year. These Guidelines will be available to all on www.iapindia.org [2] and later in the form of a book. We encourage you, fellow pediatricians, to share and disseminate them widely to all your colleagues, friends, and laypersons, to reach the parents. By the end of year, we hope to have each of these 101 guidelines available in at least 15 languages of India. Every year, 50 million new parents are added to the parent cohort of India and the Indian Academy of Pediatrics has the potential to transform the lives of their children by connecting directly to them, and that is what we will strive for.

\section{NURTURING CARE FOR EARLY CHILDHOOD DEVELOPMENT}

There is a new pandemic at large eating away at us. Something that no vaccination and immunization can control-the pandemic of non-communicable diseases diabetes, heart attack, stress, and obesity. These problems are already present in the society, now 
exacerbated by the Covid-19 pandemic and the resulting lifestyle changes [3]. Keeping these in mind, the paradigm shift I mentioned, should be from cure to prevention. Instead of being there after the act, we should aim to be community leaders, anticipating these problems, and spearheading mass programs aimed at prevention, through awareness and policy making. We pediatricians must take a leaf out of our soldiers' playbook. A soldier remains active whether it is peacetime or wartime. In the latter, he fights and in the former, he builds-bunkers, barracks, deterrent capabilities, reconnaissance data- so that the enemy thinks twice about starting the war. Our mentality, with respect to the welfare of our children, should be the same. Our fight must not be limited to actual disease but prolonging and building on good health as well. For that, doctor visits for presumingly healthy children (well child visits) must increase. Pediatricianparent interactions must go beyond illness and immunization. Well child visit concept need to be adapted and utilized for talking to parents about the junk food, screen time, sleeping hygiene, toys and plays, peer interaction, safety, security, abuse and much more.

Lancet in 2017 reported that at least $45 \%$ children under five years of age in low- and middle-income countries do not reach their optimal developmental potential [4]. For India it translates into more than 50 million children every year [5]. Most important reason is ignorance of the parents to the components of 'Nurturing Care,' especially during the first 1000 days of life i.e., from conception to 2 years, the period most crucial for neuronal connections to proliferate, activate, and mature. Any intervention during childhood extending upto 3 years of age is likely to have far reaching consequences. However, before parents, we, the community of pediatricians, need to understand the concept of Early Childhood Development and factors that protect the developing brain. We need to realize the importance of not only good health and good nutrition but equally important are the issues related to safety and security of the child, responsive parenting, and learning opportunities in the formative years of life. Only when we understand their importance, we can inculcate the concept of Nurturing Care [6] in parents.

The theme of this conference 'Nurturing care- for Early Childhood Development' will be our flagship program in 2021 and continue for next year as well. We aim to train more than 8000 pediatricians across the length and breadth of the country in spearheading the movement with a budgetary allocation of more than 4 crores. The Academy is thankful to WHO and UNICEF for copartnership in this project and for financial aid from other donors to execute this noble cause.

\section{CHILD AT SCHOOL}

A child spends almost a third of his day in school or travelling to and from it. What they do, learn, hear, or eat there, has an immense impact on their overall development. Acknowledging the importance of school and children's behavior in it, the school has to form a big part of the pediatricians' peacetime approach to child health.

Have we not seen bus-loads of kids on the roads, walking with school bags half their body weight on their backs, their spines bent over. What purpose does it serve, other than physically tire the student before even entering the school, and psychologically make him/her associate school with a tedious, unproductive chore? In the coming year, the IAP will mount a campaign to get rid of the school bag. It will be a logistical nightmare to pull off, and it may take longer than a year to do it, but if we do, I think we will sleep better knowing that we have helped lift some unnecessary burden from our children's backs.

Another factor causing children anxiety, stress and depression is the practice of giving copious amount of homework. It is so deeply ingrained into the workloads of teachers, the routine of the student, that it seems almost impossible to think of school without homework. Yet, that need not be the case. Homework tends to elevate a 30-40 hour working week (for children, presuming 6 hours of schooling every day) into a fifty, even a 60 -hour work week. Compare it with some Scandinavian countries, where the average working time for an adult is anywhere around 30-40 hours a week. It is necessary that IAP members call upon their extensive experience of research, and conduct studies to accurately assess what this excessive workload does to children's psychological health, and if it proves beneficial at all after a point. Outside the protection of labor laws, its upto us to fight to limit the working hours thrust upon a child throughout his school life.

The school boards must also be encouraged to relook at their curriculum in order to reduce workload on students. It must leave time for them to develop extracurricular interests, and the time to pursue them. One of the most important functions of the school is to let children socialize. Time must be allotted for activities that help them work in teams and develop other social skills. The safety of children encompasses three distinct places- the home, the school, the road - and each must be dealt with differently. We are open to discussion and feedback, which is why a dedicated communication channel must be opened between IAP and the education policy makers. 
Rising of the members of the Academy for health of children in this year is the focus of another flagship program launched as Mission School Uday. More than 100 pediatricians are being designated and trained to be the trainers for dissemination and sensitization of school children, their teachers and parents across the country to the three most important elements contributing to the epidemic of lifestyle disease in the coming generation, i.e., junk foods, screen time, and mental health issues.Canteens in most Indian schools cater towards kids with no parental supervision, where they are likely to buy and consume junk or ultra-processed foods. Canteens need to offer healthy, nutritional food in the middle of an active working day instead.We will also utilize this opportunity for interaction with school authorities and how to carry with the precautions after reopening the schools, as per IAP Guidelines released last year.

The ability to push through these reforms in schooling will be an unprecedented challenge for IAP, which is why we will need to be proactive, not waiting for government or other support. The IAP needs to make a school accreditation guideline - checklist consisting of the best school practices for children - and accredit schools based on it. Adoption of the accreditation system can be done through outreach to premier schools, convincing them that it is in the children's best interest, and making parents aware via advertisements and informative bite-sized videos.

\section{EDUCATION, PUBLICATION AND RESEARCH}

Capacity building of the pediatricians in the specialty areas has been a major focus of the IAP that is being achieved through its subspeciality chapters. Several fellowship programs are being run under the aegis of these chapters. Indian College of Pediatrics, a dream, instituted during the Golden Jubilee Year 2013, is now becoming a reality. Other than formalizing and accrediting all IAP fellowships and bringing them under a single umbrella, a hurricane of educational activities will be thrust through a Digital Center of Excellence (DCOE), under which e-lectures, e-modules, e-courses on all topics will be available not only for UG, PG, and fellowship students but for the practicing pediatricians as well.

Considering that more than $70 \%$ of the child patients are treated by private practitioners, this offer a huge opportunity for research in office practice. We hope to have a functional ethics committee this year to facilitate research in office practice. We are also going to launch a course on bioethics for the practitioners, to help them deal with the day-to-day ethical issues faced in office practice.

To foster an environment of research and publication in the Academy, we will be conducting workshops on research methods (for practitioners), thesis writing (for PG students and supervisors), and paper writing (for younger faculty), in all the regions of the country.

A few other things that are on cards where the work has been going on for past few months include the much awaited IAP Guidelines on media use and screen time, and prevention and treatment of rickets and vitamin D deficiency.

To encourage practitioners, postgraduates, and fresh faculty, we have launched a new Journal that will be exclusively publishing case-reports. It is the first of its kind of journal from any professional society in India. Indian Pediatrics has taken up this additional responsibility and I am proud to release the first issue today of Indian Pediatrics Case Reports, very aptly shortened as IP CaRes. Because the Journal cares for you, the Indian Academy of Pediatrics cares for you!

\section{TO CONCLUDE ...}

Dreams are never-ending, so are our deeds, but our actions are limited by the time. To over-ride that, kick-start the process, you will always find a set of people that will carry your dream.In this speech/write-up, I have just been able to give a glimpse of what I have thought has been translated into action. With you more than 30,000 pediatricians with me, I promise that I will keep on dreaming because I know that they are ultimately going to be realized with your collective efforts and wisdom, even when I am not at the helm of affairs. The torch will continue to light the lives of millions of children for whom I dream; for whom, you dream...

Jai Hind! Jai IAP!

Funding: None; Competing interests: None stated.

\section{REFERENCES}

1. Centers for Disease Control and Prevention. 1918 Pandemic (H1N1 virus). Accessed 28 January, 2021. Available from: https://www.cdc.gov/flu/pandemicresources/1918-pandemic-h1n1.html

2. Indian Academy of Pediatrics (IAP). Guidelines for Parents. Accessed 28 January, 2021. Available from: https:// iapindia.org/guidelines-for-parents/

3. Pal R, Bhadada SK. COVID-19 and non-communicable diseases. Postgrad Med J. 2020;96:429-30.

4. Britto PR, Lye SJ, Proulx KP, et al. Nurturing care: Promoting early childhood development. Lancet. 2017; 389: 91-102.

5. Countdown to 2030-Women, Children and Adolescent's health. India Country Profile. Accessed 28 January 2021.Available from: www.nurturing-care.org.

6. WHO. Operationalizing Nurturing Care for Early Child Development. Geneva, Switzerland: WHO Publications; 2019. 